\title{
JOAQUÍN DICENTA Y LUIS BONAFOUX, DOS PRECURSORES DEL PERIODISMO NARRATIVO EN ESPAÑA
}

\section{Joaquín Dicenta and Luis Bonafoux, Two Pioneers of Narrative Journalism in Spain}

\section{Joaquín Dicenta e Luis Bonafoux, dois precursores do jornalismo narrativo na Espanha}

\author{
Miguel Ángel del Arco, Universidad Carlos III de Madrid (España) \\ miguelangel.arco@uc3m.es
}

\section{Recibido: 27 de noviembre de 2019}

Aceptado: 7 de agosto de 2020

Fecha de prepublicación: 9 de octubre de 2020

\section{RESUMEN}

Este artículo reivindica las figuras de dos precursores del periodismo narrativo español en los alrededores de 1900: Joaquín Dicenta y Luis Bonafoux. Dicenta, quien además de periodista fue un autor teatral de éxito, se adelantó en varias décadas a George Orwell al relatar la vida cotidiana de los mineros, publicada por entregas en El Liberal. Bonafoux alcanzó fama como cronista y se anticipó a las coberturas en vivo por Twitter al publicar sus telegramas sobre el caso Dreyfus desde París para El Heraldo de Madrid. Estos cronistas de la bohemia modernista merecen, pues, ser rescatados del olvido e incorporados al canon del periodismo literario español.

Palabras clave: crónica; fin de siglo; Dreyfus; mineros; periodismo narrativo; Modernismo; Generación del 98. 


\section{ABSTRACT}

This article discusses two pioneers of Spanish narrative journalism from around the 1990s: Joaquín Dicenta and Luis Bonafoux Dicenta. The first, who was both a journalist and a successful playwright, was decades ahead of George Orwell when he narrated the daily life of miners, published as a serialized story in El Liberal. Bonafoux achieved great renown as a chronicler and anticipated live coverage via Twitter when he posted his telegrams regarding the Dreyfus case from Paris for El Heraldo de Madrid. These chroniclers of the modern Bohemia deserve to be rescued from oblivion and be incorporated to the canon of Spanish literary journalism.

Keywords: Chronicle; end of century; Dreyfus; miners; narrative journalism; Modernism; Generation of '98.

\section{RESUMO}

Este artigo reivindica as figuras de dois precursores do jornalismo narrativo espanhol por volta de 1900: Joaquín Dicenta e Luis Bonafoux. Dicenta, que além de jornalista foi um dramaturgo de sucesso, esteve várias décadas à frente de George Orwell no relato do cotidiano dos mineiros, publicado em fascículos em El Liberal. Bonafoux ganhou fama como cronista e antecipou a cobertura ao vivo no Twitter ao postar telegramas sobre o caso Dreyfus de Paris para El Heraldo de Madrid. Esses cronistas da boemia modernista, portanto, merecem ser resgatados do esquecimento e incorporados ao cânone do jornalismo literário espanhol.

Palavras-chave: crônica; final do século; Dreyfus; mineiros; jornalismo narrativo; Modernismo; Geração de 98.

El periodismo narrativo, o literario o interpretativo, se ha erigido en la reserva indígena de una profesión que pierde prestigio a borbotones. Lectores, autores y algunos editores más o menos románticos y comprometidos han visto en él tanto una esperanza como un refugio. Una expectativa de calidad y un amparo de la pureza. Contemplan su existencia casi como el único camino posible en un tiempo en el que la información ligera, la verdadera y la falsa, lo inunda todo, donde la cultura del clic y los mensajes automáticos se imponen a cualquier investigación decorosa.

Los convencidos lo consideran como el camino auténtico del buen periodismo, porque descubre verdades escondidas y para eso usa las armas de la literatura, la precisión expresiva y el deleite estético. Los dudosos apuntan en esa cercanía a lo literario una tendencia a la pura invención, y, por lo tanto, al olvido de la veracidad. 


\section{DISERTACIONES}

ENSAYOS

Los desafios del periodismo narrativo

ISSN: 1856-9536

Doi: https://doi.org/10.12804/revistas.urosario.edu.co/disertaciones/a.8483

Volumen 14, Número 1 / Enero-junio 2021

Versión PDF para imprimir desde

http://revistas.urosario.edu.co/index.php/disertaciones

El género se ha hecho universal a pesar de su definición conflictiva. Quizá por eso la academia no se anima a considerarlo, a atenderlo, a estudiarlo. Acaso porque teme que en su práctica y atractivo haya algo de tendencia pasajera. Pero a lo largo de la historia ha dado muestras, es verdad que a veces como un Guadiana, de permanecer. Siempre estuvo ahí porque es una manera de hacer que busca su esencia en el buen decir, en los hallazgos estilísticos, en la mirada diferente, en el compromiso con la verdad. Siempre hubo editores y lectores para el periodismo de calidad.

Ha tenido en la historia diferentes momentos propicios, de florecimiento, el Modernismo, el nuevo periodismo, los años sesenta y setenta en España alrededor de la revista mítica como Triunfo. Luego, los cronistas latinoamericanos aupados por la Fundación para el Nuevo Periodismo Iberoamericano de García Márquez. Cada una de esas etapas coincide con la existencia, o aparición, de unos nombres situados aposta entre la literatura y el periodismo, gente preparada, con talento, inteligente, creativa, inconformista, que vio en él su mejor herramienta para expresarse.

En Norteamérica hace tiempo que el periodismo literario y el de investigación siguieron caminos convergentes, antes de que Tom Wolfe nombrara al nuevo periodismo (Wolfe, 1973) y mucho antes de que Robert Boynton quisiera saber qué fue de todo eso en el nuevo nuevo periodismo (Boynton, 2015). En España, en los últimos tiempos de la dictadura, un puñado de revistas dieron acogida a buen ramillete de nombres propios, como Luis Carandell, Vázquez Montalbán, Manuel Vicent, Ricardo Cid Cañaveral, Raúl del Pozo o Francisco Umbral, que practicaron el periodismo literario sin llamarlo así.

En Europa lo practicaron desde George Orwell a Ryszard Kapuściński, pasando por John Berger. Y en Iberoamérica la cosecha es tan florida y abundante que se ha llegado a acuñar el término boom de la crónica latinoamericana, si bien tantos nombres no hacen sino tomar el testigo de Rodolfo Walsh, de García Márquez y, más allá, de José Martí.

De todos ellos reconocemos el talento, las historias inolvidables que han contado. La lista de grandes autores es grande, así que nos pusimos a delimitar el género, a ponerle nombre. A pesar de la universalidad del fenómeno no hay consenso en bautizar a ese espacio sutil entre periodismo y literatura. Incluso, alguno de sus padres miró por encima del hombro al primero, como el hermano tonto de la segunda. Lo de Tom Wolfe llegó casi al desprecio cuando dijo que el periodismo era el motel de carretera donde se dormía para llegar a la gran ciudad que sería la novela (Wolfe, 1973).

Desde entonces ha habido muchos intentos de nombrar y de definir ese ámbito brumoso y necesario. A los habituales títulos de periodismo literario, nuevo periodismo o literatura periodística, se han ido sumando más etiquetas: literary news writing, nuevo nuevo periodismo o slow journalism.

Todos probablemente en un intento de delimitar, acotar, aclarar o, incluso, curar una cierta mala conciencia académica. Y con Paul Many (1996) se ensayó una lista más amplia, donde se sumaron conceptos y sincretismos, en un entretenido juego de espejos y sobrenombres: periodismo artístico, periodismo lento (Rosique \& Barranquero, 2015), ensayo de ficción, ficción factual, literatura de hechos, ficción de la realidad, reportaje en profundidad, periodismo de incidencia, periodismo participativo, periodismo personal, documental periodístico, narrativa dramática, la nueva no ficción, la novela de no ficción, el periodismo cultural. También, periodismo interpretativo, como acuñó Concha Fagoaga en uno de los primeros manuales sobre el género (Fagoaga, 1982). 


\section{DISERTACIONES}

ENSAYOS

Los desafios del periodismo narrativo

ISSN: 1856-9536

Doi: https://doi.org/10.12804/revistas.urosario.edu.co/disertaciones/a.8483

Volumen 14, Número 1 / Enero-junio 2021

Versión PDF para imprimir desde

http://revistas.urosario.edu.co/index.php/disertaciones

A la pluralidad de nombres hay que añadir las confusiones generadas en torno al uso del término crónica, que, en distintos países latinoamericanos, sobre todo tras el boom, se ha impuesto con tal fuerza que ha ocupado el propio concepto de periodismo narrativo (Angulo Egea, 2014). Y un cierto malentendido lleva a contraponer la crónica en España, ligada a la actualidad y con formato breve, a la latinoamericana, de más de largo aliento, quizá más cercana al reportaje. Dos miradas distintas o no tanto. Pero, a pesar de imprecisiones y de la abundancia de autonombrados cronistas, el compromiso con la historia singular es muy parecido a un lado y a otro del océano.

Como apunta Leia Guerriero, periodismo narrativo es el que toma algunos recursos de la ficción -estructuras, climas, tonos, descripciones, diálogos, escenas- para contar una historia real y que, con esos elementos, monta una arquitectura tan atractiva como la de una buena novela o un buen cuento (Guerriero, 2016). Pero sobre todo es periodismo, descubrimiento, búsqueda de la verdad, compromiso con el intento de entender el mundo y explicarlo.

Anterior al nuevo periodismo, por supuesto al nuevo nuevo periodismo y mucho antes que el pujante grupo de los nuevos cronistas de Indias, cuando no estaba nombrado ni definido, hubo un periodismo brillante, atrevido, de largo aliento, inconformista y crítico. Lo practicaron periodistas preparados, admirados y envidiados en su tiempo, que fueron borrados por el canon imperante y hoy son unos auténticos desconocidos. Asumieron, entonces, en los alrededores de 1900, el compromiso con la verdad, con explicar a sus lectores lo que pasaba, y por qué pasaba, con los recursos de la literatura. Podemos ver sus crónicas, sorprendentemente modernas y actuales, en los grandes periódicos españoles de aquellos años: El Liberal, El Heraldo de Madrid, El País, El Imparcial.

\section{Cronistas bohemios}

En el libro Cronistas bohemios (Del Arco, 2017) se reúne a un grupo de literatos que ejercieron ese periodismo narrativo, sin nombrarlo como tal, quizá sin saberlo, unos autores que convivieron con movimientos literarios tan importantes como la Generación del 98 y el Modernismo. Hoy los nombres de Joaquín Dicenta y Luis Bonafoux son desconocidos, pero en aquel tiempo eran más leídos y admirados incluso que los que han pasado a la historia de la literatura. En la prehistoria del periodismo en español descubrimos con asombro que contaban la realidad con las armas de la literatura, empeñados en hacer lo que muchos años después haría el nuevo periodismo.

Tanto Dicenta como Bonafoux, en los últimos años del siglo xix y los primeros del xx, eran personalidades seguidas y admiradas. Tuvieron amplio reconocimiento en el teatro, la novela, el ensayo y el periodismo. Aquí los traemos a este artículo por reporteros, por pioneros de ese periodismo de calidad. Ambos usaron, hace más de cien años, recursos de la ficción - estructuras, climas, tonos, descripciones, diálogos, escenas- para contar lo que pasaba en la sociedad de aquel tiempo.

Ambos reportearon sendos momentos de periodismo ejemplar. Joaquín Dicenta quiso saber cómo vivían los mineros en la mina, su día a día. Luis Bonafoux contó con todo detalle el asunto Dreyfus. Uno bajó a la mina con los mineros y contó su dura vida. Otro siguió como corresponsal en París el escándalo más mediático de su época. Probablemente los dos periodistas se adelantaron, gracias a su talento, a lo que pediría muchos años después el mejor periodismo narrativo.

Joaquín Dicenta (1862-1917) se embarcó en un proyecto que debería estudiarse en las redacciones y en la academia. Era en 1903 la estrella tanto del periódico El Liberal, donde escribía diariamente, como del ambiente literario madrileño. El líder de las tertulias de café, el autor teatral más representado. A pesar de eso, y de su edad ya 


\section{DISERTACIONES}

ENSAYOS

Los desafios del periodismo narrativo

ISSN: 1856-9536

Doi: https://doi.org/10.12804/revistas.urosario.edu.co/disertaciones/a.8483

Volumen 14, Número 1 / Enero-junio 2021

Versión PDF para imprimir desde

http://revistas.urosario.edu.co/index.php/disertaciones

veterana, inició una cobertura periodística que desde hoy se ve sorprendente e ilustrativa: conocer in situ las rutinas de los mineros de Linares (Jaén). Fue, convivió, investigó, preguntó y descubrió. Como Kapuściński. El resultado fue una visión completa, la novela de una mina, en nueve entregas que se publicaron durante los meses de enero y febrero de 1903. Nueve textos, entre la crónica y el reportaje, donde relata la vida y trabajos de los mineros.

Usó metáforas, aportó detalles, logró trasladar al lector a las casas de los mineros, al fondo de la mina, a los bares donde enterraban sus miserias. Mostró cómo era la sociedad que le tocó vivir, hizo periodismo de investigación, recurrió a fuentes de primera mano, estuvo en el lugar de los hechos.

En 1888 había empezado a colaborar en La Piqueta, uno de los semanarios clave para la difusión del germinalismo, y en La Avispa. Al año siguiente en El Radical. Luego formó parte del equipo de redacción de Las Dominicales del Libre Pensamiento, donde coincidió con nombres que serían también significativos en la llamada Edad de Oro del periodismo español, como Francos Rodríguez, Miguel Moya, Luis Bonafoux, Luis París, Ricardo Fuente, Manuel Paso o Mariano de Cavia.

La lista de medios donde puso su firma es larga. Además de los señalados, podemos citar: La Regencia, La Opinión, La Caricatura, La Iberia, El Imparcial, La Época, El Universal, El Mundo, La Opinión, El Heraldo de Madrid, Germinal, La Esfera, La Correspondencia de España, El Globo, Vida Nueva, La Ilustración Obrera, La Avispa, Vida Galante, Ahí Va o Alma Española. Hizo conocido el seudónimo Don Hermógenes. También dirigió La Democracia Social, Germinal y El País. Y desde 1908 escribió todos los días en El Liberal.

En algún momento Joaquín Dicenta fue, al mismo tiempo, director de medios tan significativos como la revista Germinal o el diario El País y también el autor teatral de más éxito. Como escritor tocó todos los géneros, como periodista, también. Su figura brilló en esos años que bordean el siglo más que ninguna otra. Fue mentor, hermano mayor del grupo del 98. Azorín se refiere a él en términos de admiración en el legendario artículo donde se habla por primera vez de la Generación del 98 (Martínez, 1913).

Su rastro lo encontramos en obras y memorias de Baroja, Valle Inclán, Zamacois, Gómez Carrillo, Rubén Darío y cuantos se han ocupado del cambio de siglo, del 98 y del Modernismo. Si faltara alguna muestra de su importancia, Rafael Pérez de la Dehesa afirma que "para la Generación del 98 el drama de Joaquín Dicenta, 'Juan José', tuvo la significación del 'Hernani' victorhuguesco' (1970).

Arturo Mori escribe de Joaquín Dicenta en La prensa de nuestro tiempo (1943, p. 59): "Era tan autor como periodista... Una crónica de Dicenta significaba la nota palpitante del día ciudadano: un crimen, un estreno, un traspiés político, un libro. En un estilo romántico, pero moderno, de alma castiza y temple universal, humano y revolucionario, más cerca siempre de los humildes que de sus magnates".

Tuvo Joaquín Dicenta una vida muy movida, aventurera: "En su biografía hay puñaladas, un rapto, un suicidio", escribe Eduardo Zamacois en sus memorias (1903, p. 196). Lo describe como gran bebedor, mujeriego y con una inevitable tendencia a la reyerta.

A Dicenta se le atribuían proezas tales como la de cortarle a Valle Inclán sus melenas, en una trifulca nocturna. El autor de Luces de bohemia (1920) hubo de afeitarse el cráneo y esperar a que volviera a crecer. Vendió los libros para festejar a una modistilla y al día siguiente se instaló con ella, pero enseguida se arrepintió. Es exactamente el trasunto de su novela Encarnación (1913), aunque en la ficción no fue modistilla, sino una prostituta que se enamoró de él, la sacó del local donde trabajaba y la llevó a su casa para luego arrepentirse. Un drama con mucho 


\section{DISERTACIONES}

ENSAYOS

Los desafios del periodismo narrativo

ISSN: 1856-9536

Doi: https://doi.org/10.12804/revistas.urosario.edu.co/disertaciones/a.8483

Volumen 14, Número 1 / Enero-junio 2021

Versión PDF para imprimir desde

http://revistas.urosario.edu.co/index.php/disertaciones

de autobiografía, donde contaba las andanzas de un grupo de jóvenes bohemios. En esa novela se pueden rastrear lugares, tabernas, el hospital, los jóvenes literatos del $98 . .$. toda una radiografía de la sociedad madrileña.

Zamacois escribe en sus memorias: "La vida de Dicenta es vendaval desatado; el demonio seductor de lo imprevisto guía sus pasos; todo le seduce; sobre sus noches y sus días, el desorden tiene encendida eternamente su lámpara roja” (1903, p. 196).

Rubén Darío también compartió con él noches y desórdenes y escribe: “Con Joaquín Dicenta fuimos compañeros de gran intimidad, apolíneos y nocturnos. Fuera de mis desvelos y expansiones de noctámbulo, presencié fiestas religiosas palatinas; teníamos inenarrables tenidas culinarias, de ambrosías y sobre todo de néctares, con el gran don Ramón María del Valle Inclán" (2000, p. 67).

Dicenta fue, además, el ídolo de la juventud radical del fin de siglo. Si su drama Juan José le dio la fama y el nombre a partir de 1896, el año en que fue estrenado con gran éxito, su actividad periodística hacía que encabezara cuanto nuevo proyecto se iniciaba. Tras La Piqueta, o Democracia Social o Germinal, vinieron más tarde $E l$ Intransigente, La Lucha y El Radical.

La historia de los mineros debió impresionarlo porque también publicaría otro texto sobre el fondo de la mina en la revista Alma Española, esta vez el 8 de noviembre de 1903, en el que describía las míseras condiciones en que se encontraban los mineros de Almadén (Ciudad Real).

Las técnicas que usó como reportero respondían seguramente a una metodología por inventar, pero que él puso en práctica más por preparación que por mera intuición. Los procedimientos de búsqueda de información, su valoración dentro del contexto de la realidad social y política, su empeño en dar voz a quienes no la tenían, su rigurosa investigación y la clara exposición de lo observado requieren mucha preparación y una gran predisposición, así como experiencia, dominio del oficio y del lenguaje.

Lo que hizo Joaquín Dicenta en Linares aquellas Navidades fue ejercer de periodista total, curioso y comprometido. Todas las entregas tenían un título común, bien visible en mayúsculas, en la primera página del periódico, "Entre mineros". Sin embargo, cada una de ella se centraba en un aspecto, una secuencia, de modo que la visión de conjunto que pretendía se asentaba en la convicción de observar de cerca, de profundizar, de no dejar ningún rincón por registrar.

El 2 de enero apareció la primera, subtitulada "A flor de tierra". La segunda, el 6 de enero, "De cara a la mina". La tercera, el 12 de enero, “Pozo abajo". La cuarta, "Desde el fondo", el 16 de enero. En la quinta pone el periodista su foco en uno de los protagonistas, "El hampón”, y aparece el 19 de enero. Una vez narrado cómo es la mina y la vida de quienes trabajan en ella, se fija en su contexto, en las consecuencias, y publica, el 22 de enero y el 4 de febrero, dos nuevas entregas, "La fundición" y "Los emplomados". El 13 de febrero aparece el texto subtitulado "Lluvia de plomo" y el 21, "Al partir", donde cierra su viaje, su investigación y su proyecto.

Pretendía conocer directamente los diferentes ambientes de la ciudad minera, de modo que visitó pozos, fábricas, calles, casas de mineros, tabernas, oficinas. Habló con viejos, niños, mujeres, picadores, capataces. Fue reportero cuando apenas empezaba la profesión de periodista, fue enviado especial cuando ni se conocía tal figura. Y con todo lo observado y vivido escribió las nueve entregas que publicó El Liberal y que resultan hoy una verdadera lección de buen periodismo. Se adelantó así en varias décadas al famoso libro de George Orwell El camino a Wigan Pier (1937), en el que el célebre escritor y periodista narraba de primera mano las condiciones de la clase obrera y de los mineros del norte de Inglaterra. 


\section{DISERTACIONES}

ENSAYOS

Los desafios del periodismo narrativo

ISSN: 1856-9536

Doi: https://doi.org/10.12804/revistas.urosario.edu.co/disertaciones/a.8483

Volumen 14, Número 1 / Enero-junio 2021

Versión PDF para imprimir desde

http://revistas.urosario.edu.co/index.php/disertaciones

En "A flor de tierra" contaba su llegada a Linares, pintaba el cielo azul y el aire de fiesta tras las Pascuas, el trajín bullicioso de los obreros vestidos de domingo mezclado con el afán siniestro de los que "el hatillo al hombro, el cigarro de papel sujeto entre los labios, se dirigían a la mina, a jugar su existencia durante doce horas contra un jornal de doce reales" (Dicenta, 1903, p. 1).

La pintura es concienzuda en ese texto, cuida que el dato sea claro, repara en paradojas y hace comparaciones, "besos de luz y cantos de pájaros" (Dicenta, 1903, p. 1) con la negrura sepulcral de los fondos mineros. Se fija en los puestos de turrón de la Navidad y ve la coloración pálida de la piel, la tristeza humilde de los ojos, el matiz blancuzco de los labios: "Los niños de esa raza tienen la cabeza gorda, el cuello delgado, las piernas curvadas, la sangre empobrecida de los padres" (Dicenta, 1903, p. 1). Es crónica de reportero con gusto por la pincelada: "El sombrero sobre los ojos, la colilla entre los dientes y el cuchillo en la faja" (Dicenta, 1903, p. 1).

En "De cara a la mina" se centra en el barrio obrero, mira sus calles y aporta una descripción pormenorizada de las viviendas. Entra en el cuarto de un minero y dice cómo es: una habitación de tres metros, un ventanuco cerrado, sillas, clavos en la pared sosteniendo atavíos humildes, y un cubo que sirve de baño, palangana y escupidera. En esas habitaciones desprovistas de claridad, de higiene, duermen seis hombres "sin otra cama que sus petates extendidos por tierra igual que en las cárceles públicas" (Dicenta, 1903, p. 1).

En la tercera entrega, el reportero se mete en la mina y titula su experiencia "Pozo abajo". Cuenta sus propias impresiones mientras contempla los lavaderos, confiesa el impacto de la bajada al pozo, anota los comentarios del capataz que lo acompaña. Está introduciendo en su texto diálogos como hará 50 años después el nuevo periodismo. Y digresiones, descripciones totalmente cinematográficas.

Plantea su texto como la continuación de la crónica anterior y deja la puerta abierta a que el lector espere otra, fórmula de las novelas por entregas, de los folletines, aplicada al periodismo. Describe al maquinista que maneja la jaula que baja y sube, y confiesa que sintió "miedo e impulsos de retroceder" (Dicenta, 1903, p. 1) e introduce una nota de humor cuando el capataz ve su miedo: le dice que los cables a veces fallaban pero que ese día eran nuevos: "La afirmación irónica y terrible para los que bajan diariamente resultaba consoladora para mí" (Dicenta, 1903, p. 1). En su relato hace un verdadero despliegue de sensaciones, para acercar al lector al descubrimiento de un mundo desconocido. Para ello apela a todos los sentidos: el chirrido de la jaula, el agua goteando por las paredes, la oscuridad, la luz del candil, la humedad, un patético paisaje de maderas, andamios, boquetes profundos, ruidos tenebrosos, máquinas perforadoras, voces, un horizonte de tinieblas, 500 metros, luces a lo lejos y el ruido de los picos. Era el fondo de la mina.

Exactamente el título de la siguiente entrega. Así hila la serie, de modo que tras experimentar esa bajada a los infiernos sale de la jaula y es recibido por el ingeniero en el fondo de la mina: "Un francés cuyo nombre he olvidado, no me ocurre igual con sus corteses atenciones y agradabilísima conversación” (Dicenta, 1903, p. 1). Y seguido por el francés y precedido del capataz se encamina el reportero hacia el interior de la mina: "Hundíanse mis pies en una alfombra de fango líquido" (Dicenta, 1903, p. 1). Echa mano de metáforas para mostrar la paradoja de encontrar una cierta belleza en ambiente tan hostil: "La luz de nuestros candiles convertía en arroyuelos de plata las vetas de plomo y en joyería inapreciable las sales que cristalizaban con variada geometría sobre las orillas del túnel” (Dicenta, 1903, p. 1). 


\section{DISERTACIONES}

ENSAYOS

Los desafios del periodismo narrativo

ISSN: 1856-9536

Doi: https://doi.org/10.12804/revistas.urosario.edu.co/disertaciones/a.8483

Volumen 14, Número 1 / Enero-junio 2021

Versión PDF para imprimir desde

http://revistas.urosario.edu.co/index.php/disertaciones

Apunta lo que ha visto: hombres con el torso desnudo arrastrarse a poner la mecha sin tiempo para escapar, a cortadores de material tumbados boca arriba. Y las consecuencias, que se rompa una soga, que muera el cargador de barrenos. Una puesta en escena dramática para reflexionar sobre lo poco que vale la vida del minero.

También se ocupa, en una suerte de periodismo total, panorámico, de las formas de diversión del minero, con el alcohol como referente. Se fija en la figura del hampón, que da el título a su quinta entrega. El plan del reportero fue recorrer los sitios donde los mineros se reunían al volver de su trabajo: tabernas, bodegones, colmados, cafés de camareras, café cantantes... "tales son los centros que el esclavo de la mina escoge para engañar su estómago con manjares innutritivos, aturdir su cerebro enraquitecido con 'medios' de aguardiente, satisfacer sus anhelos estéticos con guitarresca música, con canciones rebosantes de estupidez" (Dicenta, 1903, p. 1).

Así es el escenario que pinta: un hombre y 5 o 6 entretenedoras de la casa. Aquel pide botellas de jerez "sacando de entre la camisa su pañuelo, convertido en bolsón, y del bolsón duros y más duros” (Dicenta, 1903, p. 1). Es un minero hampón, es decir, un bohemio de la mina, un solitario, "un hijo prodigo de la mina presto a dilapidar en rapidísimas horas de goce el caudal humilde que horas sin cuento de trabajo le permiten recoger en la mina" (Dicenta, 1903, p. 1). Aporta Dicenta el dato de que, en las oficinas, fuente de la que parte la información, ignoran los nombres de los trabajadores.

En la sexta entrega de su serie minera visita una fundición. Una apuesta para cerrar el círculo, y ahí descubre que no mejoran precisamente las condiciones de trabajo. No hay una bajada en una jaula por un pozo infernal, pero el calor del plomo fundido no es menos duro. En la séptima da un paso más en su investigación que lo lleva a una fábrica de plomo y muestra el influjo nocivo de ese material en el organismo de los que allí realizan su trabajo.

En la octava historia minera habla de los emplomados, los hombres que sufren en sus cuerpos las secuelas de la mina. Habla con siete hombres, siete testigos, siete fuentes que van a la fonda donde se hospeda el reportero, que se percata de que lo más duro no está en el fondo de la mina, porque allí abajo están los que pueden trabajar. Los que le hablan no pueden, "son residuos humanos" (Dicenta, 1903).

Utiliza Dicenta elementos de la literatura: la sorpresa, diálogos y metarrelato. Recoge el testimonio de un ricacho de Linares, quien afirma que "el obrero se queja sin razón, el trabajo de los hornos no es tan malo como ellos dicen. Si se toman precauciones nadie teme por la salud" (Dicenta, 1903, p. 1). Tras el discurso paternalista, el periodista se fija en un perro flaco, tísico, casi moribundo: - “Vaya perro", dije. "Ah, vivirá poco", dijo el ricacho. - "Perro que anda por estos sitios no dura un año". Así termina su crónica, sin añadir una palabra más, demostrando dominio del tempo y de los golpes de efecto.

En esta novena y última muestra deja otra lección de periodismo. En su búsqueda de las fuentes adecuadas: incluye el testimonio de un articulista del lugar, un exminero llamado Molina que escribe en el periódico El Defensor de Linares y cuenta que aún hay mineros que trabajan en peores condiciones que las que el reportero de Madrid ha visto. Que aún peor que envenenarse con el gas es que un día llegue el estallido de un cartucho, un hundimiento, que "les deja para pedir limosna en el arroyo" (Dicenta, 1903, p. 1).

El mérito de Joaquín Dicenta, sus recursos de periodismo moderno, los diálogos incluidos en el texto, la acción, la narración en lugar de la foto fija, es mayor si tenemos en cuenta la fecha de publicación de la serie, cuando apenas en España estaba cambiando el llamado periodismo de opinión, ideológico, hacia el de información. 


\section{DISERTACIONES}

ENSAYOS

Los desafíos del periodismo narrativo

ISSN: 1856-9536

Doi: https://doi.org/10.12804/revistas.urosario.edu.co/disertaciones/a.8483

Volumen 14, Número 1 / Enero-junio 2021

Versión PDF para imprimir desde

http://revistas.urosario.edu.co/index.php/disertaciones

\section{Pluriempleados}

Su amigo y compañero de aventuras periodísticas, Luis Bonafoux Quintero (1855-1918), probablemente fue el periodista español más brillante, admirado, seguido, odiado y temido de los últimos años del siglo xix y los primeros del xx. Famosísimo en su tiempo, también está hoy completamente olvidado. Fundó y dirigió periódicos, fue el primer corresponsal en París de un periódico madrileño, El Heraldo de Madrid, fue el primero que habló en España del caso Dreyfus y de Zola, el único que se atrevió a enfrentarse a un crítico tan temible y poderoso como Leopoldo Alas, Clarín. Fue perseguido por sus escritos en Puerto Rico, Cuba, España, Francia e Inglaterra. Viajó por medio mundo: Puerto Rico, La Habana, París, Madrid, Salamanca, Argelia, Roma, Marruecos, Berlín, Venecia, Reinosa, Londres, y escribió lo que vio. Afirma José Luis Cano (1990) que "sus crónicas provocaban escándalo, amenazas y duelos a pistola".

Lo llamaban la Víbora de Asnieres porque en ese pueblecito de las afueras de París vivía y por su afilada pluma. Escribía con un estilo ágil, directo y conciso, que usaba tanto para mostrar la realidad española como para arremeter contra quienes consideraba los responsables de sus males, el Ejército, la Iglesia católica y la clase política que condujo a España al desastre del 98. Pero también utilizaba ese estilo inmisericorde contra todo lo que consideraba vulgar o atrasado.

Para hacernos una idea de la celebridad e influencia que alcanzó en su tiempo, apuntaremos solamente unos detalles: se le consideró discípulo de Émile Zola y ayudó al entonces joven y desconocido José Martínez Ruiz, 'Azorín', para que pudiera escribir en las páginas de El País. Fue el primer periodista en describir las reuniones del Club Anarquista Internacional, en Londres, donde conoció e hizo amistad con el teórico y militante anarquista italiano Enrique Malatesta. El escritor guatemalteco Enrique Gómez Carrillo, que lo conoció bien, lo recuerda en su libro de memorias en el popular café de Fornos: "Allí estaba Bonafoux, el terrible Bonafoux, vibrante, parlero, endiablado, atrabiliario, divertido, bilioso y muy simpático, en suma, a pesar de los esfuerzos que hacía por no serlo, o al menos por no parecerlo" (1921, p. 43).

Fue uno de los periodistas más cultos, lúcidos y osados de entre siglos, para muchos considerado en aquel tiempo el moderno Quevedo. Por eso, sorprende más que hoy sea un absoluto olvidado. Su vida anduvo entre las penurias económicas y la persecución política. Tuvo que irse de Puerto Rico, después de ser apedreado; y de Madrid, y residió en Francia hasta que Clemenceau, ministro del Interior y de la Guerra, lo invitó a marcharse, el 20 de julio de 1915. Acabó en Londres y allí murió de tristeza, en octubre de 1918, porque no soportó la pérdida de su mujer, Ricarda Encarnación Valenciaga, apenas dos meses antes.

Entre sus constantes viajes y estancias periodísticas en medio mundo y su personalidad cambiante, pintoresca y heterodoxa, no es fácil reconstruir su cronología vital. Por eso, dice su biógrafo José Fernando Dicenta, que se le conoce mejor situándolo "frente a los acontecimientos más importantes de su tiempo, de los que fue lúcido testigo cuando no protagonista" (Dicenta, 1974, p. 16).

Efectivamente conoció de cerca, investigó y narró los hechos más importantes de una época apasionante, el cruce de siglos. Su pluma afilada, culta y deslenguada, se ocupó igual de presidentes de gobierno que de literatos, de generales que de independentistas, de anarquistas que de gente del teatro. 


\section{DISERTACIONES}

ENSAYOS

Los desafios del periodismo narrativo

ISSN: $1856-9536$

Doi: https://doi.org/10.12804/revistas.urosario.edu.co/disertaciones/a.8483

Volumen 14, Número 1 / Enero-junio 2021

Versión PDF para imprimir desde

http://revistas.urosario.edu.co/index.php/disertaciones

Cuenta José Fernando Dicenta en su biografía que el primer duelo lo tuvo en El Paréntesis. En la prensa española finisecular no era fácil ser independiente, como pretendía el polémico Bonafoux. O se era conservador o progresista, monárquico o republicano, católico o anticlerical. Y en función de la ubicación, tanto geográfica como ideológica, los periodistas se dedicaban a dar, o palos o bombos, dependiendo a quién se dedicaran los escritos, a enemigos o a amigos. Bonafoux escribía con dureza y sin compromiso. Se decía que mojaba la pluma en bilis, y así tituló precisamente uno de sus libros, Bilis, y otro Palos y bombos.

Fue colaborador buscado en la mayoría de las publicaciones de la época: El Globo, El Heraldo, El Liberal, El País, Alma Española, Vida Nueva, Don Quijote, Madrid Cómico, además de El Solfeo, Gil Blas y El Satiricón o La Discusión. En todos se mostró como un polemista incansable y para muchos de sus coetáneos fue el mejor cronista de todos. Su cultura, su andamiaje intelectual, su pluma y su genio le hacían tan temible como admirado. Fundó periódicos como El Español y El Intransigente, editados en Madrid, de los que no quedan ejemplares en las hemerotecas, y $L a$ Campaña y El Heraldo de París, de los que apenas queda un número en la hemeroteca municipal de Madrid. Fue también redactor jefe de El Globo y El Resumen.

Bonafoux firmaba sus crónicas con su nombre o con seudónimos, el de Aramis o el de Luis de Madrid. Era el alma de El Español, pero no logró salvarlo. De modo que el cierre del semanario lo dejó en una dramática situación económica. Hizo un peregrinaje por las redacciones y le abrió las puertas El Resumen. Lo cuenta en su autobiografía, que publicó en el número 26 de Los Contemporáneos, la colección de libritos que emuló a la novela corta (Bonafoux, 1909).

Un periodista importante de la época, Isidoro Fernández Flores, 'Fernanflor', le ofreció la corresponsalía de El Liberal, en París, y empezó a telegrafiar una crónica diaria. Le aconsejó su mentor que firmara con seudónimo, ya que tenía muchos odios entre las gentes del oficio. Empezó a firmar como Luis de Madrid.

En su calidad de corresponsal y periodista español fue invitado a una de las célebres cenas que organizaba la prestigiosa revista literaria La Plume, y en el café Du Palais se sentó Bonafoux entre Zola y Mallarmé. Lo cuenta en su correspondiente crónica, y describía en la misma cena la presencia de Paul Verlaine: "Trajeado de harapos, con enorme bufanda al cuello y sombrero ancho sepultado hasta las cejas, adormecido por el alcohol y cojeando por el reuma" (Bonafoux, 2000).

En la capital francesa fue contratado junto a otros escritores españoles, como Alejandro Sawa o Ricardo Fuente, para confeccionar el famoso diccionario Garnier, encargados de escribir biografías de personajes. Aparte, tenía la corresponsalía de El Heraldo de Madrid, y escribía artículos que enviaba a La Correspondencia, de Puerto Rico, y a El Mundo, de La Habana. Así mismo, componía crónicas que le pedían los periódicos madrileños El País y El Progreso, La Época, Alma Española, Don Quijote o Vida Nueva. Y escribía libros, cuentos y novelas.

Lo reclamaban porque su nombre deslumbraba y era homenajeado por sus coetáneos. El 22 de enero de 1899 se publicó una de las volanderas que escribía el también bohemio y periodista Manuel Bueno en El Globo, bajo el seudónimo de Lorena: "Bonafoux es la única pluma ágil, sincera, burlona, que orea con ráfagas geniales nuestro periodismo anodino y latoso" (Bueno, 1899).

Decía de él Rubén Darío que "tiene larga fama. Hay quienes, en Río Janeiro, o en Tánger, leen tales o cuales diarios sólo por el artículo de Bonafoux. Y lleva la carga de su talento, con talento" (2000). Y lo ponía como ejemplo ante la tesitura de designar un lugar para el periodismo y otro para la literatura: "La obra de Bonafoux demuestra 


\section{DISERTACIONES}

ENSAYOS

Los desafios del periodismo narrativo

ISSN: 1856-9536

Doi: https://doi.org/10.12804/revistas.urosario.edu.co/disertaciones/a.8483

Volumen 14, Número 1 / Enero-junio 2021

Versión PDF para imprimir desde

http://revistas.urosario.edu.co/index.php/disertaciones

lo vano de la diferencia que ha querido hacerse entre escritores y periodistas. No existe después de todo sino esto: hay periodistas que saben escribir y periodistas que no saben escribir; hay quienes tienen ideas y quienes no" (Darío, 2000).

También habló el maestro del Modernismo de sus crónicas: "Las crónicas de Bonafoux serían así sonetos, rondeles, letrillas, sin rimas: aladas, picantes, ligeras, pesadas, con su poco de miel, con su poco de amargura, tal como hubieran podido complacer a cierto ruiseñor alemán que anidó en la peluca de Voltaire según confesión propia" (Darío, 1921). Y lo comparaba con Heine, pero también con Cervantes.

El 5 de enero de 1895 estalló el affaire Dreyfus: a las siete de la mañana, el capitán Alfredo Dreyfus era esposado por un escuadrón de la Guardia Republicana para ser degradado en público, antes de ser confinado en la isla del Diablo. Bonafoux lo siguió muy de cerca, al principio sin darle mucha importancia. Le preocupaban más la desastrosa política colonial del gobierno de España y contra ella clamaba desde París. Además de criticar duramente la pérdida de Cuba y de Filipinas, se enfrentó a la crispada opinión pública, "al histrionismo de la prensa que reclamaba represalias infames, que incluso aplaudieron el fusilamiento del doctor Rizal, al que acusaban de ser el responsable de la insurrección tagala" (Bonafoux, 1897). Bonafoux afirmaba que Rizal "expió el crimen de haber publicado un libro contra los frailes del archipiélago" (Bonafoux, 1897). Y criticaba duramente al general Polavieja: "Fusilar no es vencer".

Las posturas de Bonafoux le valieron no pocas denuncias, pedían su extradición, lo llamaban antipatriota y separatista por apoyar la autonomía de las colonias, le amenazaron con no dejarle escribir más en muchos periódicos si no se retractaba. No lo hizo.

En 1896 se revisó el caso Dreyfus. En 1897 el hermano del excapitán, Mateo Dreyfus, denunció al comandante Esterhazy por alta traición y exigió que se revisara el proceso. Luis Bonafoux lo contó con detalle en las páginas de El Heraldo de Madrid y las de todos los medios donde colaboraba: se implicó y denunció. El 11 de enero de 1898 Émile Zola publicó el famoso artículo "Yo acuso". Bonafoux analizó el proceso como un cirujano, como un buen periodista, estudió las actas, se aprendió las conclusiones, entrevistó a los testigos y mostró la actitud de los partidos franceses, críticos con Zola.

En una crónica de El Heraldo, titulada "La protesta de Zola", publicada el 12 de septiembre de 1899, se hizo eco del grito airado "que el insigne novelista Emilio Zola lanzó contra la sentencia que ha condenado a Dreyfus. Es un documento monumental, la honrada protesta de la indignada conciencia del primer escritor francés contemporáneo" (Bonafoux, 1899, p. 1). Dice que cuando se conozca el proceso de Rennes, se verá que no existe "más execrable monumento a la infamia humana en la historia" (Bonafoux, 1899, p. 1).

El 6 de octubre de 1898 escribió una crónica en El Nuevo País, que título "De vuelta a la vida", en ella habla "del barco que ha de prestarse para conducir al condenado en la isla del Diablo a Francia, va a ofrecer un espectáculo maravilloso, encargado de buscar a un muerto, un hombre asesinado ante dos millones de compatriotas va a traernos por obra y gracia de la santa justicia un resucitado, redivivo, apto para volver al honor" (Bonafoux, 1998, p. 1).

Contaba en su texto de El Nuevo País que él estaba en París en aquella época del calvario de Dreyfus, "se decían cosas horribles, un viento de locura corría por los bulevares, un oficial francés había vendido a su país al enemigo y quería descuartizarlo, quemarlo" (Bonafoux, 1998, p. 1). Recuerda que el juicio fue a puerta cerrada, que lo condenaron con crueldad, a la exoneración, a la degradación, "pero vuelve para ser juzgado de nuevo por un tribunal 


\section{DISERTACIONES}

ENSAYOS

Los desafios del periodismo narrativo

ISSN: $1856-9536$

Doi: https://doi.org/10.12804/revistas.urosario.edu.co/disertaciones/a.8483

Volumen 14, Número 1 / Enero-junio 2021

Versión PDF para imprimir desde

http://revistas.urosario.edu.co/index.php/disertaciones

competente, y la nave que lo trae es un altar flotante que lleva en su seno, como el tabernáculo, toda la justicia humana y a cuanto podemos aspirar de la justicia divina" (Bonafoux, 1998, p. 1).

Envió crónicas del proceso, acreditado como corresponsal de El Heraldo de Madrid. El 10 de septiembre de 1899 cuenta cómo comunican la sentencia absolutoria a Dreyfus y apunta las palabras de este, tísico: "Consuele usted a mi mujer para que no se entristezca, mi cuerpo es ya inabordable al sufrimiento" (Bonafoux, 1899, p. 1). A base de telegramas hilados, como si fuera la trabazón de un Twitter hoy, va aportando datos, hechos, descripciones, diálogos. Explica que "la sentencia responde al propósito de no condenar a los generales, aunque quedó claro ya en 1894 que varios jueces no vieron la culpabilidad de Dreyfus" (Bonafoux, 1899, p. 1). El día siguiente, el 11 de septiembre, también por telégrafo, completa su relato sobre la sentencia del consejo de guerra de Rennes. Describe el júbilo y satisfacción, apunta, para completar el hilo, que un académico dice en Le Figaro que nadie creerá que dos oficiales el Ejército hayan podido votar a favor de la absolución si la culpabilidad hubiera estado demostrada. En otro, minutos después, dice que Le Figaro publica un escrito en el que afirma que la esposa de un general visitó uno por uno en sus casas a los jueces de Rennes, solicitando que condenaran a Dreyfus por unanimidad, y que la casa de Jaime Dreyfus, hermano del condenado, fue apedreada. En otro telegrama cuenta las reacciones en Bruselas, Ostende, Roma, Budapest, Nueva York, Filadelfia, en donde se ve unanimidad en apoyar a Dreyfus y criticar la sentencia de Rennes, "tan solo en Francia siguen con sus alaridos de hiena satisfecha los obcecados por la pasión y el encono", escribe en su crónica que titula "Efectos de la sentencia” (Bonafoux, 1899, p. 1).

Todos los días de ese septiembre del último año del siglo xix aporta detalles de la sentencia y de las reacciones que se produjeron: el recurso de casación, el consejo de ministros que abordó la cuestión del indulto, las resoluciones, el eco y seguimiento por parte de la prensa, las conductas y alegaciones dudosas de jueces y ministros.

Una muestra de su estilo la vemos en el texto que publicó el día 19, titulado "¡Yo, vil!". Escribe en primera persona: "Pase que el ser Marcial Cabrea, secretario de redacción de La Ley, de Santiago de Chile, deseando que yo colabore - no me dice cómo, pero supongo que gratis- me llame 'el displicente y gruñón cronista español de París'. Pero no me parece tan pasadero que un señor francés de Alicante me haya remitido el duplicado de una carta que dice que envió al director del Heraldo" (Bonafoux, 1899, p. 1). Sigue relatando en ese texto que dicha carta no está firmada: "Acaso porque el señor franchute temió que fuera a verlo a Alicante, como si yo me dedicara a arrear acémilas". Parece que el señor anónimo estaba furioso con Bonafoux porque "me parece una iniquidad la sentencia del consejo de guerra de Rennes y una lástima que la cuna de las revoluciona por la libertad, la igualdad y la fraternidad se deje trasformar en nido de sapos y de culebrones" (Bonafoux, 1899). Cuenta el cronista en su diatriba que le parece odioso al que manda la carta sin firma que "la prensa española y la de todo el mundo haya protestado contra las iluminaciones y los regocijos demostrados en París y en Rennes por haber vuelto a condenar tan injusta como inicuamente a un inocente que, por el crimen de ser judío, pasó cinco años en el infierno de la isla del Diablo". Saca su conocida bilis cuando añade: "Pues si sospecha usted, especie de gaznápiro, que su carta no daría resultado porque soy vil y tengo mala fe, ¿a que la escribió usted?”. Y explica su posición al referirse a otra carta de las muchas que recibía a diario, en este caso de apoyo: "Pero aunque nadie me felicitase, no cambiaría la satisfacción de haber dado en este periódico el primer grito que dio España a favor de la inocencia de Dreyfus, aunque recoja por todo provecho que el Eco de París me llame 'víbora que se pasea por París' o el gobierno del paquidermo político Dupuy indique a la Embajada de España que yo corría peligro de salir para la frontera, todo por pensar libremente en la "capital del mundo civilizado". 


\section{DISERTACIONES}

ENSAYOS

Los desafíos del periodismo narrativo

ISSN: 1856-9536

Doi: https://doi.org/10.12804/revistas.urosario.edu.co/disertaciones/a.8483

Volumen 14, Número 1 / Enero-junio 2021

Versión PDF para imprimir desde

http://revistas.urosario.edu.co/index.php/disertaciones

Antes de ser el primer periodista español que contó el caso Dreyfus ya era bien conocido como cronista y ya había comenzado su encarnizado pulso con Clarín, el crítico al que nadie osaba discutir. Bonafoux llegó a asegurar que La Regenta (1884) era un mal plagio de Madame Bovary (1852), lo que le llevó no solo al aborrecimiento personal, sino al juzgado. Y dividió a los círculos literarios entre clarinistas y aramistas, una polémica y una división que era fácilmente trasladable al pulso generacional, entre la llamada Gente Vieja y los miembros modernistas de la Gente Nueva.

La Gente Nueva se mostraba abierta a todo tipo de tendencias y escuelas, dispuestos a luchar por la república democrática en política y por una nueva estética en el arte. Frente a ellos, la Gente Vieja representaba la reacción, el catolicismo, el conservadurismo y la monarquía en política; y el realismo en la literatura. Y el crítico Leopoldo Alas era el dueño del canon.

De ese largo y accidentado enfrentamiento escribió Luis París en su libro Gente nueva: "Ambos tenían la misma mala intención, pero Bonafoux era más rápido, más ágil y tenía más gracia que Clarín” (París, 1888).

En esa obra lo describe Luis París como "un tipo muy original en todo cuanto constituye su fisonomía humana y literaria, es mordaz con los enemigos y cruel hasta desgarrar sus carnes" (1888). Y también: "Su polémica con Clarín ha mantenido durante mucho tiempo la atención constante de los círculos literarios" (París, 1888). Recoge la frase que oyó en un círculo de literatos: "Aunque Bonafoux no tuviera otros méritos, bastaríale haber sido el protestante del pontificado de Clarín” (París, 1888).

Fue considerado por muchos el rey de los cronistas. Solía afirmar en sus crónicas y artículos que ni tenía ni necesitaba amigos, pero lo cierto es que pasaban por París a visitarlo desde Rubén Darío y Carmen de Burgos a todas las figuras relevantes de la época. Era implacable con la vida social y política española. Sus crónicas llegaron a provocar escándalos, denuncias, amenazas e, incluso, duelos a pistola. Como crítico teatral titulaba sus escritos de los estrenos Los crímenes estrenados anoche.

En 1915 el gobierno francés, a petición del gobierno belga, lo expulsó. El motivo, un artículo que publicó en El Heraldo de París, hablando de las posaderas de la reina de los belgas. El 20 de julio de 1915, salió con su familia hacia Londres, donde se instaló. El 31 de julio de 1918 murió Ricarda, su mujer. Bonafoux se derrumbó y el 28 de octubre de ese mismo año murió en su domicilio londinense, a los 64 años. Sus hijos lo enterraron en el cementerio de Central Green.

El Heraldo de Madrid recoge en su portada, el 31 de octubre, en un largo texto sin firmar, las reacciones de los diferentes periódicos ante la muerte de su corresponsal. Cita el homenaje que le hizo El Liberal al "escritor más personal, más ático, más sabio y completamente irónico de la lengua castellana. Bonafoux llevó a la crónica una calidad, una percepción sutil y una cultura jamás superadas. Sin miedo y sin tacha, se atrevió a decir lo que ningún otro escritor hubiera osado, con limpia pero firme crudeza" (anónimo, 1918, p. 1).

Quizá también por eso lo llamaban la Víbora de Asnieres.

\section{Conclusiones}

Tanto Joaquín Dicenta como Luis Bonafoux ejercieron el liderazgo en los ambientes literarios y periodísticos de la España de entre siglos. Fueron dos figuras con luz propia en unos años que concentraron a grandes nombres. Dirigieron algunos de los principales medios, emprendieron aventuras informativas, a ellos recurrían los editores 


\section{DISERTACIONES}

ENSAYOS

Los desafíos del periodismo narrativo

ISSN: 1856-9536

Doi: https://doi.org/10.12804/revistas.urosario.edu.co/disertaciones/a.8483

Volumen 14, Número 1 / Enero-junio 2021

Versión PDF para imprimir desde

http://revistas.urosario.edu.co/index.php/disertaciones

por su experiencia y su talento. Sus méritos curriculares, la importancia de sus obras y la admiración y respeto que les tuvieron sus coetáneos deberían ser suficientes para estar en cualquier canon cultural y ser referentes. Sin embargo, hoy soy prácticamente desconocidos.

Ambos escribieron de manera habitual en los principales periódicos y fueron conocidos por ello. Fueron reporteros, cronistas, enviados especiales, articulistas y literatos al mismo tiempo. Usaron métodos de investigación complejos y completos para descubrir buenas historias, cultivar fuentes y denunciar injusticias.

Los dos usaron de modo natural las armas de la literatura (Herrscher, 2012) para interpretar lo que pasaba en la sociedad que les tocó vivir. Mezclaron diálogos, aportaron inesperados puntos de vista, ensayaron metáforas, buscaron comparaciones, recurrieron a la psicología de los personajes, contaron historias, dieron voz a quienes no tenían púlpito, fueron vigilantes del poder.

Uno y otro fueron tan periodistas como literatos, se preocuparon tanto de decir rápidamente como de decir bien, tanto de hacerse entender como de empeñar un estilo propio. Ejercieron quizá sin saberlo el periodismo narrativo. En las crónicas de Dicenta y Bonafoux que se analizan en este artículo ya estaba el ornitorrinco de Juan Villoro (2006), había novela, reportaje, cuento, entrevista, retórica y teatro. Es decir, investigación, personajes, vida, hechos, datos, escenario, diálogos y estilo.

\section{Referencias}

1. (31 de octubre de 1918). In memorian a la muerte de Luis Bonafoux. El Heraldo de Madrid, p. 1.

2. Angulo Egea, M. (2014). Crónica y mirada: aproximaciones al periodismo narrativo. Libros del K.O.

3. Bonafoux, L. (10 de septiembre de 1899). El proceso Dreyfus. El Heraldo de Madrid, p. 1.

4. Bonafoux, L. (11 de septiembre de 1899). Efectos de la sentencia. El Heraldo de Madrid, p. 1.

5. Bonafoux, L. (12 de septiembre de 1899). La protesta de Zola. El Heraldo de Madrid, p. 1.

6. Bonafoux, L. (19 de septiembre de 1899). jYo, vil! El Heraldo de Madrid, p. 1.

7. Bonafoux, L. (1909). Los contemporáneos. De mi vida y milagros. Biblioteca Nacional de España.

8. Bonafoux, L. (13 de septiembre de 1988). Después de la sentencia. El Heraldo de Madrid.

9. Bonafoux. L. (6 de octubre de 1998). De vuelta a la vida. El Nuevo País, p. 1.

10. Bonafoux, L. (1999). Bilis. http://www.cervantesvirtual.com/obra-visor/bilis--0/html/

11. Bonafoux, L. (2000). Huellas literarias. http://www.cervantesvirtual.com/obra/huellas-literarias--0/

12. Boynton, R, S. (2015). El nuevo nuevo periodismo. Conversaciones sobre el oficio con los mejores escritores estadounidenses de no ficción. Edicions Universitat de Barcelona.

13. Cano, J. L. (1990). La España de Bonafoux. Ediciones Libertarias.

14. Darío, R. (1921). Letras. Obras completas. Vol. VIII. Recopilación de artículos periodísticos. Editorial Mundo Latino.

15. Darío, R. (2000). La vida de Rubén Darío escrita por él mismo. http://www.cervantesvirtual.com/obra-visor/ la-vida-de-ruben-dario--0/html/ff17bf78-82b1-11df-acc7-002185ce6064_2.html

16. Del Arco, M. A. (2017). Cronistas bohemios, la rebeldía de la Gente Nueva. Taurus.

17. Dicenta, J. (1903). Entre mineros. A flor de tierra. El Liberal, p. 1.

18. Dicenta, J. (6 de enero de 1903). Entre mineros. De cara a la mina. El Liberal, p. 1. 


\section{DISERTACIONES}

19. Dicenta, J. (12 de enero de 1903). Entre mineros. Pozo abajo. El Liberal, p. 1.

20. Dicenta, J. (16 de enero de 1903). Entre mineros. Desde el fondo. El Liberal.

21. Dicenta, J. (19 de enero de 1903). Entre mineros. El hampón. El Liberal, p. 1.

22. Dicenta, J. (22 de enero de 1903). Entre mineros. La fundición. El Liberal.

23. Dicenta, J. (4 de febrero de 1903). Entre mineros. Los emplomados. El Liberal.

24. Dicenta, J. (13 de febrero de 1903). Entre mineros. Lluvia de plomo. El Liberal.

25. Dicenta, J. (21 de febrero de 1903). Entre mineros. Al partir. El Liberal, p. 1.

26. Dicenta, J. (1913). Encarnación. Librería de los Sucesores de Hernando.

27. Dicenta, J. F. (1974). Luis Bonafoux. La víbora de Asnieres. cvs.

28. Fagoaga, C. (1982). Periodismo interpretativo: el análisis de la noticia. Editorial Mitre.

29. Gómez Carrillo, E. (1921). Treinta años de mi vida. Libro 3º. La miseria de Madrid. El Mundo Latino.

30. Guerriero, L. (2016). Zona de obras. Anagrama.

31. Herrscher, R. (2012). Periodismo narrativo. Cómo contar la realidad con las armas de la literatura y qué enseñan las vidas y las obras de los grandes maestros de la no ficción. Edicions Universitat de Barcelona.

32. Many, P. (1996). Literary journalism: newspapers last, best hope. The Connecticut Review, (1), 59-69.

33. Martínez Ruiz, J. (13 de marzo de 1913). La Generación del 98. ABC.

34. Mori, A. (1943). La prensa española de nuestro tiempo. Ediciones Mensaje.

35. París, L. (1888). Gente Nueva. Crítica inductiva. Imprenta Popular.

36. Pérez de la Dehesa, R. (1970). El grupo germinal: una clave del 98. Taurus.

37. Rosique-Cedillo, G., \& Barranquero-Carretero, A. (2015). Periodismo lento (slow journalism) en la era de la inmediatez. Experiencias en Iberoamérica. El Profesional de la Información, 24(4), 451-462.

38. Villoro, J. (22 de enero de 2006). Entre la literatura y el periodismo. La crónica, ornitorrinco de la prosa. La Nación. https://www.lanacion.com.ar/cultura/la-cronica-ornitorrinco-de-la-prosa-nid773985/

39. Wolfe, T. (1973). El nuevo periodismo. Anagrama.

40. Zamacois, E. (1903). De mi vida, recuerdos, historias de mis libros, ensayos dramáticos, críticas. Casa Editorial Sopena. 